\title{
Review
}

\section{Platelet Rich Plasma- mechanism of action and clinical applications}

\author{
Cristina N. Cozma ${ }^{1}$, Laura Raducu ${ }^{1,2}$, Cristian R. Jecan ${ }^{1,2}$ \\ ${ }^{1}$ Prof. Dr. Agrippa Ionescu Clinical Emergency Hospital, Department of Plastic and Reconstructive Surgery, \\ Bucharest, Romania \\ ${ }^{2}$ Carol Davila University, Department of Plastic and Reconstructive Surgery, Bucharest, Romania
}

\begin{abstract}
Platelet-rich plasma (PRP) is a blood-derived fraction containing high level of platelets, a high concentration of leukocytes and growth factors. PRP therapy has been growing as a viable treatment alternative for a number of clinical applications and has a potential benefit for use in wound healing.

Nowadays platelet rich plasma is used in stimulating wound healing in skin and soft tissue ulcerations, accelerating wound healing in diabetic patients and facilitating bone proliferation in orthopedic and trauma surgery. It has also applications in maxillofacial surgery, spinal surgery, plastic and esthetic surgery, heart surgery and burns.

This review of the literature shows a limited number of studies realized on humans that sustain PRP applications in orthopedic and plastic surgery. As the use of PRP increases, more properly structured clinical studies are necessary to confirm the results and to establish clearly the techniques of preparing, the conditions and the clinical indications of applying this therapy.
\end{abstract}

Keywords: platelet rich plasma, wound healing, growth factors 


\section{Introduction}

Platelet-rich plasma (PRP) is a derived fraction of the blood that contains high concentrations of platelets and growth factors with mitogenic and chemotactic proprieties (1). The first use of PRP injections was in 1987 in an open heart surgery (2), in the following years being used in promoting wound healing in maxillofacial surgeries. A great impact was shown in 2009 when PRP was used as an adjuvant of healing ankle injuries in sport players, becoming a "new treatment" for sports related injuries (3).

Nowadays platelet rich plasma is used in stimulating wound healing in skin and soft tissue ulcerations, accelerating wound healing in diabetic patients and facilitating bone proliferation in orthopedic and trauma surgery. It has also applications in maxillofacial surgery, spinal surgery, plastic and esthetic surgery, heart surgery and burns (4).

There are numerous studies that research the mechanism of action and demonstrate efficacy in placebo trials. One of the main interest points of using PRP in plastic surgery is in healing chronic wounds including diabetic and pressure ulcers.

\section{Discussion}

In this review article, we discuss the clinical application of PRP in orthopedic and plastic surgery based on a review of the current literature. This review discusses published human studies available on PubMed found using the keywords "platelet rich plasma/PRP and clinical applications in wounds". The result revealed eighty-three studies, sixty-four with clinical applications in orthopedic surgery. Only studies available in English were used.

\section{Mechanism of action}

The main mechanism of action of PRP is through platelets, which besides their well-known function in homeostasis, release also factors that promotes angiogenesis and tissue repair (5). Secretory granules of the platelets contain growth factors, coagulation factors, cytokines, adhesion molecules and integrins. Releasing of the active growth factors is realized through degranulation of alfa granules (1).

The main growth factors included in alfa granules are: platelet derived growth factor (PDGF), platelet derived endothelial growth factor (PDEGF), vascular endothelial growth factor (VEGF), epidermal growth factor (EGF), insulin like growth factor (IGF), platelet derived angiogenesis factor (PDAF), transforming growth factor(TGF), keratinocyte growth factor (KGF), fibroblast growth factor (FGF), connective tissue growth factor (CTGF), tumor necrosis factor alpha (TNF- $\alpha$ ), interleukin $1 \beta$ (IL $1 \beta$ ) and interleukin 8 (IL8) (5).

All these growth factors stimulate healing by attracting cells in the new formed matrix and triggering division of the cells. Another process involved in wound healing might be the role of PRP in suppressing the cytokine release that limits inflammation, and also in interaction with macrophages to promote tissue healing, regeneration and epithelialization (1).

Platelet rich plasma also contains a small quantity of leucocytes which synthesize interleukins and antimicrobial peptides with an antibacterial role $(4,6)$.

\section{Production of PRP}

Platelet rich plasma has a safety profile being produced from autologous blood with minimal risks for disease transmission, immunogenic reactions and cancer $(7,8)$. Patients who are considered to be candidates for using PRP must undergo a minor hematological evaluation to exclude blood disorders or platelet dysfunction (9).

PRP can be produced very easy using patient's blood, a centrifuge and an activator formed of thrombin or calcium (10). Nowadays there are several 
kits for producing PRP and the process is simple. Apart from injections, PRP might be also use as a gelatinous platelet gel by activation with thrombin or calcium, being easier to use in soft tissue injuries and wounds (11).

Clinically valuable PRP contains approximately one million platelets per microliter, lesser or greater concentrations have not been shown to have better results in improving wound healing (12).

\section{Clinical use of platelet rich plasma}

In the last two decades platelet rich plasma was largely used in maxillofacial surgery. Recent developments in research of the regenerative effects of PRP on bones, tendons, cartilage, muscle and skin have attracted interest in fields as orthopedic and plastic surgery (13).

Nowadays PRP has an important use in orthopedic surgery, especially in tendon injuries accelerating tendon healing through growth factors (14), even though there are some studies that show no improvement in arthroscopic rotator cuff repair (15), in tendinopathies or muscle injuries $(16,17)$. PRP action in tendon injuries might be explained through the higher concentrations of VEGF which stimulates angiogenesis and tendon vascularization. Furthermore, leucocytes stimulate macrophage migration and reduce tissue inflammation. PRP plays also a therapeutic role for cartilage pathology, especially in conservative treatment of cartilage degenerative lesions and osteoarthritis $(18,19)$.

Apart from the important use in orthopedic and trauma surgery, platelet rich plasma plays an important role in plastic surgery as an adjuvant therapy for chronic, diabetic and pressure ulcers. Some studies showed a benefic action of PRP applied on ulcers. For example, a retrospective cohort study showed that PRP improves healing in severe diabetic neuropathic ulcers compared with standard of care $(20,21)$. Another paper described improvement in healing a patient with a diabetic ulcer that failed to heal using other treatment modalities (22). Two studies involving patients with chronic ulcers showed that PRP improves local vascularization and promotes epithelization $(23,24)$.

Studying the way of action, it has been shown that PRP stimulates the activity of keratinocytes, cells with important roles in epithelization during the healing processes (4). This effect improved epithelization not only in acute wounds, but also in chronic wounds or burns. Treatment of pressure ulcers was also improved by PRP compared with classical saline solution, minimizing complications and the time of healing (25).

Regarding soft tissues defects, PRP plays an important role in diminishing edema, ecchymosis, bacterial load through its antibacterial and antiinflammatory proprieties, reducing infections and additional complications (5).

The sustained release of large quantities of growth factors, cytokines, and other mediators found in platelet rich plasma may help in stimulating wound healing and resolving chronic inflammation (1)

Not all studies support the use of PRP in wound healing. For example, two studies from 1991 and 2002 showed no significant improvement in diabetic foot ulcerations in comparison with classical treatment $(26$, 27).

PRP is used as an adjuvant therapy for chronic wounds. The most important steps in wound healing are debridement, offloading and frequent dressing changes, procedures that transform a chronic wound into an acute wound (1).

Debridement represents an important step, removing all the devitalized and necrotic tissues, reducing also the bacterial load, and leaving a healthy tissue (21). It is also important to eliminate other factors which impede healing like pressure, friction and sheer. After preparing the wound bed, PRP is applied as a gel or injected in the wound (1). 
Even though studies showed that PRP brings an improvement in orthopedic treatments and wound healing it is difficult to compare its efficacy in multiple studies due to additional factors. The composition of PRP is different for every patient, for every device involved in preparation, including the time and method of storage and the interaction with other materials (7).

Further studies are required to optimize its preparation and use, and to evaluate the best effective technique of using it to improve healing.

\section{Conclusions}

Platelet rich plasma represents a biological therapy that restarts and accelerates the healing process of chronic ulcers recalcitrant to other treatments, providing an improvement of patient quality of life.

Having the advantages of biocompatible safety, low cost, simple preparation and clinical effectiveness more clinical randomized controlled trials should focus on the use of platelet rich plasma as an adjuvant therapy in the management of chronic wounds and in discovering various conditions in which its use has merit.

\section{References}

1. Lacci KM, Dardik A. Platelet-Rich Plasma: Support for Its Use in Wound Healing. Yale J Biol Med. 2010; 83(1): 1-9. PMID: 20351977

2. Jalowiec JM, D'Este M, Bara JJ, Denom J, Menzel U, Alini M, Verrier S, Herrmann M. An In Vitro Investigation of Platelet-Rich Plasma-Gel as a Cell and Growth Factor Delivery Vehicle for Tissue Engineering. Tissue Eng Part C Methods. 2016; 22(1): 49-58. PMID: 26467221

\section{https://doi.org/10.1089/ten.tec.2015.0223}

3. Osterman C, McCarthy MB, Cote MP, Beitzel K, Bradley J, Polkowski G, Mazzocca AD. Platelet-
Rich Plasma Increases Anti-inflammatory Markers in a Human Coculture Model for Osteoarthritis. Am J Sports Med. 2015; 43(6): 1474-84. PMID: 25716226

\section{https://doi.org/10.1177/0363546515570463}

4. Kim SA, Ryu HW, Lee KS, Cho JW. Application of platelet-rich plasma accelerates the wound healing process in acute and chronic ulcers through rapid migration and upregulation of cyclin A and CDK4 in HaCaT cells. Mol Med Rep. 2013; 7(2): 476-80. PMID: 23242428

5. Rozman P, Bolta Z. Use of platelet growth factors in treating wounds and soft-tissue injuries. Acta Dermatovenerol Alp Pannonica Adriat. 2007; 16(4): 156-65. PMID: 18204746

6. Edelblute CM, Donate AL, Hargrave BY, Heller LC. Human platelet gel supernatant inactivates opportunistic wound pathogens on skin. Platelets. 2015; 26(1): 13-6. PMID: 24433255 https://doi.org/10.3109/09537104.2013.863859

7. Marques LF, Stessuk T, Camargo IC, Sabeh Junior N, dos Santos L, Ribeiro-Paes JT. Platelet-rich plasma (PRP): methodological aspects and clinical applications. Platelets 2015; 26(2): 101-13. PMID: 24512369

https://doi.org/10.3109/09537104.2014.881991

8. Philippart P, Meuleman N, Stamatopoulos B, Najar M, Pieters K, De Bruyn C, Bron D, Lagneaux L. In vivo production of mesenchymal stromal cells after injection of autologous plateletrich plasma activated by recombinant human soluble tissue factor in the bone marrow of healthy volunteers. Tissue Eng Part A. 2014; 20(1-2): 16070. PMID: 23924315

https://doi.org/10.1089/ten.tea.2013.0244

9. Everts PA, Knape JT, Weibrich G, Schönberger JP, Hoffmann J, Overdevest EP, Box HA, van 
Zundert A. Platelet-rich plasma and platelet gel: a review. J Extra Corpor Technol. 2006; 38(2): 17487. PMID: 16921694

10. Fukaya M, Ito A. A New Economic Method for Preparing Platelet-rich Plasma. Plast Reconstr Surg Glob Open. 2014; 2(6): e162. PMID: 25289355

https://doi.org/10.1097/GOX.0000000000000109

11. Stanco D, Vigano' M, Croiset SJ, De Girolamo L. Applications and limits of platelet-rich plasma in sports related injuries. J Biol Regul Homeost Agents. 2012; 26(2 Suppl 1): 53S-61S PMID: 23648199

12. Cervelli V, Scioli MG, Gentile P, Doldo E, Bonanno E, Spagnoli LG, Orlandi A. Platelet-rich plasma greatly potentiates insulin-induced adipogenic differentiation of human adiposederived stem cells through a serine/threonine kinase Akt-dependent mechanism and promotes clinical fat graft maintenance. Stem Cells Transl Med. 2012; 1(3): 206-20. PMID: 23197780 https://doi.org/10.5966/sctm.2011-0052

13. Alsousou J, Ali A, Willett K, Harrison P. The role of platelet-rich plasma in tissue regeneration. Platelets. 2013; 24(3): 173-82. PMID: 22647081 https://doi.org/10.3109/09537104.2012.684730

14. Wang JH, Nirmala X. Application of Tendon Stem/Progenitor Cells and Platelet-Rich Plasma to Treat Tendon Injuries. Oper Tech Orthop. 2016; 26(2): 68-72. PMID: 27574378

https://doi.org/10.1053/j.oto.2015.12.008

15. Gwinner C, Gerhardt C, Haneveld H, Scheibel M. Two-staged application of PRP in arthroscopic rotator cuff repair: a matched-pair analysis. Arch Orthop Trauma Surg. 2016; 136(8): 1165-71. PMID: 27379974

https://doi.org/10.1007/s00402-016-2499-4
16. Andia I, Maffulli N. Muscle and tendon injuries: the role of biological interventions to promote and assist healing and recovery. Arthroscopy. 2015; 31(5): $\quad$ 999-1015. $\quad$ PMID: 25618490 https://doi.org/10.1016/j.arthro.2014.11.024

17. Hall MP, Ward JP, Cardone DA. Platelet rich placebo? Evidence for platelet rich plasma in the treatment of tendinopathy and augmentation of tendon repair. Bull Hosp Jt Dis. 2013; 71(1): 54-9. PMID: 24032584

18. Marmotti A, Rossi R, Castoldi F, Roveda E, Michielon G, Peretti GM. PRP and Articular Cartilage:A Clinical Update. BioMed Research International 2015; 2015: 542502. PMID: 26075244

19. Tuan RS, Chen AF, Klatt BA. Cartilage regeneration. J Am Acad Orthop Surg. 2013; 21(5): 303-11. PMID: 23637149 https://doi.org/10.5435/00124635-20130500000007

20. Yilmaz I, Akkaya S, Isyar M, Batmaz AG, Guler O, Oznam K, Ugras A, Mahiroğullari M. Is there a treatment protocol in which platelet-rich plasma is effective? J Orthop. 2016; 13(4): 316-21. PMID: 27408512

https://doi.org/10.1016/j.jor.2016.06.027

21. Akingboye AA, Giddins S, Gamston P, Tucker A, Navsaria H, Kyriakides C. Application of Autologous Derived-Platelet Rich Plasma Gel in the Treatment of Chronic Wound Ulcer: Diabetic Foot Ulcer. J Extra Corpor Technol. 2010; 42(1): 20-29. PMID: 20437788

22. Salemi S, Rinaldi C, Manna F, Guarneri GF, Parodi PC. Reconstruction of lower leg skin ulcer with autologous adipose tissue and platelet-rich plasma. J Plast Reconstr Aesthet Surg. 2008; 61(12): 1565-1567. PMID: 18694662 https://doi.org/10.1016/j.bjps.2008.04.048 
23. Crovetti G, Martinelli G, Issi M, Barone M, Guizzardi M, Campanati B, Moroni M, Carabelli A. Platelet gel for healing cutaneous chronic wounds. Transfus Apher Sci. 2004; 30(2): 145151. PMID: 15062754

https://doi.org/10.1016/j.transci.2004.01.004

24. O’Connell SM, Impeduglia T, Hessler K, Wang XJ, Carroll RJ, Dardik H. Autologous platelet-rich fibrin matrix as cell therapy in the healing of chronic lower - extremity ulcers. Wound Repair Regen. 2008; 16(6): 749-56. PMID: 24527280 https://doi.org/10.1111/j.1524-475X.2008.00426.X

25. Singh R, Rohilla RK, Dhayal RK, Sen R, Sehgal PK. Role of local application of autologous platelet-rich plasma in the management of pressure ulcers in spinal cord injury patients. Spinal Cord. 2014; 52(11): 809-1. PMID: 25179658 https://doi.org/10.1038/sc.2014.144

26. Casati L, Celotti F, Negri-Cesi P, Sacchi MC, Castano P, Colciago. Platelet derived growth factor (PDGF) contained in Platelet Rich Plasma (PRP) stimulates migration of osteoblasts by reorganizing actin cytoskeleton. Cell Adh Migr. 2014; 8(6): 595-602. PMID: 25482626 https://doi.org/10.4161/19336918.2014.972785

27. Jeong DU, Lee CR, Lee JH, Pak J, Kang LW, Jeong BC, Lee SH. Clinical applications of platelet-rich plasma in patellar tendinopathy. Biomed Res Int. 2014; 2014: 249498. PMID: 25136568 